Portland State University

PDXScholar

$11-4-1991$

\title{
The Effect of Otitis Media on Articulation in Expressive Language-Delayed Children
}

Marla Lohr-Flanders

Portland State University

Follow this and additional works at: https://pdxscholar.library.pdx.edu/open_access_etds

Part of the Speech and Hearing Science Commons

Let us know how access to this document benefits you.

\section{Recommended Citation}

Lohr-Flanders, Marla, "The Effect of Otitis Media on Articulation in Expressive Language-Delayed Children" (1991). Dissertations and Theses. Paper 4365.

https://doi.org/10.15760/etd.6222

This Thesis is brought to you for free and open access. It has been accepted for inclusion in Dissertations and Theses by an authorized administrator of PDXScholar. Please contact us if we can make this document more accessible: pdxscholar@pdx.edu. 
AN ABSTRACT OF THE THESIS OF Marla Lohr-Flanders for the Master of Science in Speech communication: Speech and Hearing Science presented November 4, 1991.

Title: The Effect of Otitis Media on Articulation in Expressive Language-Delayed Children

APPROVED BY MEMBERS OF THE THESIS COMMITTEE:

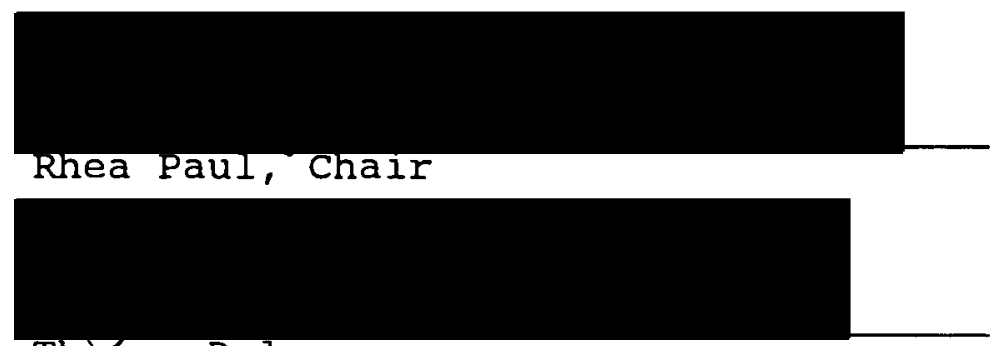

Thơnas Dolan

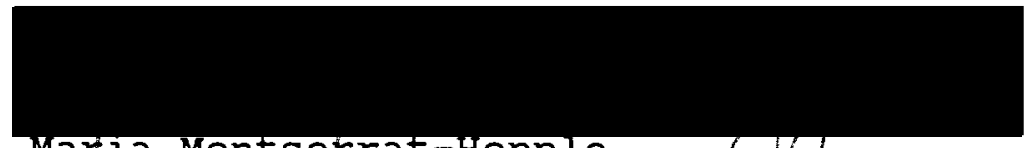

Maria Montserrat-Hopple
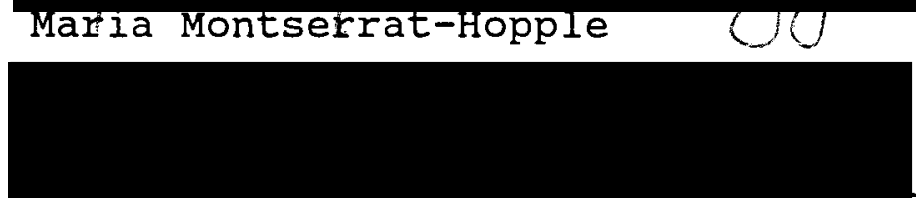

cord sengstake

Researchers have long been concerned with the effects of otitis media on speech and language acquisition because of the high correlation of a mild to moderate hearing loss during the time period that fluid (effusion) may be in the middle ear. Middle-ear effusion would prevent many of the auditory messages from accurately reaching the nervous system (zinkus, 1986). Deprived of the ability to discern 
the subtle acoustic differences that provide information for phonetic contrasts, a child's speech acquisition may differ from children who do not experience such losses.

The present study examined the relationship between an early history of otitis media and the speech development of two groups of children: one, a group of 27 "late-talking" toddlers who, while otherwise normal, had not reached normal language milestones by age 2 ; and a second group of toddlers with normal language development. Within these two diagnostic groups, each of the subjects was placed into one of two subgroups: a subgroup with a reported history of "ear infections" and a subgroup without such a history. When the children were 3 years old, they were seen again and evaluated using the Goldman Fristoe Test of Articulation (GFTA). A similar group of 25 children who had a history of normal language development was also examined.

The study addressed the following questions:

1. How does the mean number of reported episodes of "ear infections" in the late-talker group compare to the number in the normal-language group?

2. Are there significant differences between scores on the GFTA between groups of late talkers with and without a history of middle-ear involvement at 3 years of age, suggesting a difference in the acquisition of speech sounds based on history of middle-ear involvement?

3. Are there significant differences between scores on the GFTA between groups of normal talkers with and 
without a history of middle-ear involvement at 3 years of age, suggesting a difference in the acquisition of speech sounds based on a history of middle-ear involvement?

The mean number of ear infections reported by the parents of the late-talker and normal-talker subjects was compared. While the late-talker subjects were reported to have slightly more ear infections than the normal-talker subjects, this difference did not reach a significant level. A two-tailed $t$ test comparing the mean GFTA percentile rank score of normal-talker and late-talker groups was performed. A significant difference $(\underline{p}<.05)$ was found between the two groups, indicating that the late talkers were much poorer in articulation than the normal talkers. An analysis of variance was performed to determine if an interaction between the diagnostic groups and their history of otitis media could be found. No significance was found, suggesting that ear infections alone did not seem to account for the poorer articulation in the late talkers.

The results of this study indicate that children who demonstrate expressive language delays at age 2 are at risk for immature articulatory development at age 3. No evidence that a history of otitis media adds to this risk or constitutes any additional risk of speech disorder was found.

otitis media continues to be an ongoing problem, especially for young children. Researchers disagree about the long-term effects of otitis media and its contribution 
to articulation and language problems. While the results of this study indicate that a history of otitis media does not constitute any additional risk of articulation disorder in expressive language-delayed children, it may be one of many variables, such as family history, that interact with speech and language that may increase the already substantial risk for articulation delay in such children. 
THE EFFECT OF OTITIS MEDIA ON ARTICULATION IN EXPRESSIVE LANGUAGE-DELAYED CHILDREN

by

MARLA LOHR-FLANDERS

A thesis submitted in partial fulfillment of the requirements for the degree of

\author{
MASTER OF SCIENCE \\ in \\ SPEECH COMMUNICATION : \\ SPEECH AND HEARING SCIENCE
}

Portland State University

1992 
TO THE OFFICE OF GRADUATE STUDIES:

The members of the committee approve the thesis of

Marla Lohr-Flanders presented November 4, 1991.

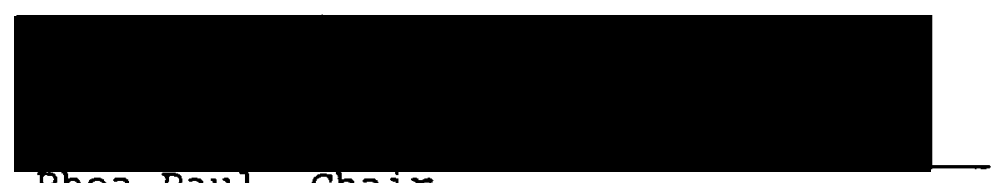

Rhea Paul, Chair

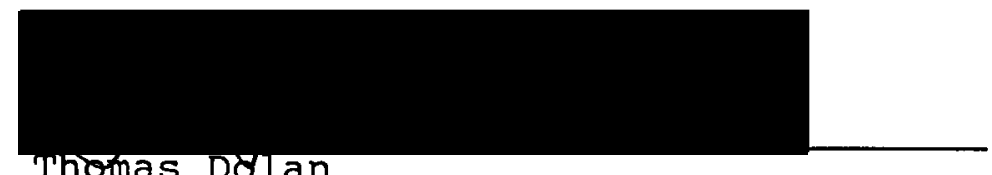

Thomas Dolan

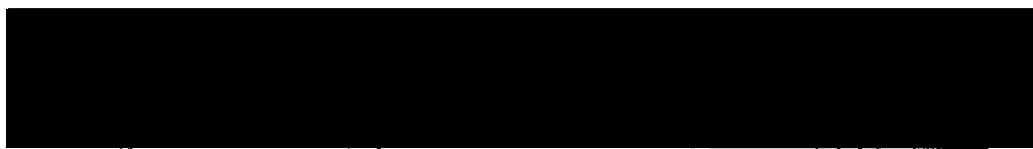

Maria Montserrat-Hopple
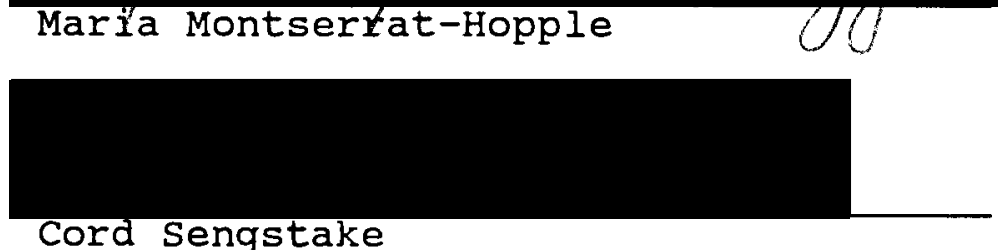

APPROVED :

Cord Sengstake

Theodore G. Grove, Chair, Department of Speech Communication

c. William savery, Interim Vicgf Provost for Graduate stuales and Research 


\section{ACKNOWLEDGEMENTS}

I would like to thank my thesis committee membersDr. Thomas Dolan, Maria Montserrat-Hopple, and Dr. Cord Sengstake-for their insight and advice.

My thesis advisor, Dr. Rhea Paul, deserves much more than thanks for her tireless energy and dedication to the mentor concept. For my entire graduate career she has been a source of inspiration, a role model.

Finally, I would like to thank my partner, Kermit, who listened patiently and encouraged me throughout this whole process. Without his support and the support of our friends and family this process would have been much more difficult for me. 
TABLE OF CONTENTS

PAGE

ACKNOWLEDGEMENTS

LIST OF TABLES

LIST OF FIGURES

\section{CHAPTER}

I

INTRODUCTION

Statement of Purpose . . . . . .

Definition of Terms . . . . . . .

II REVIEW OF THE LITERATURE . . . . . . . .
Epidemiology . . • . . . . . . .
Studies Investigating the Effect of Otitis Media on Language Development
Studies Investigating the Effect of Otitis Media and Delayed Speech/Articulation

Summary . . . . . . . . . . .

Subject Recruiting

Description of subjects

Procedures . . . . . . . . .

Intake Procedures

Outcome Procedures

Procedures for Present Study

Equipment 
CHAPTER

IV

RESULTS AND DISCUSSION • • • • • • • • • •

Results . . . . . . . . . . . . .

Reported History of Ear Infections

The Effect of Otitis Media on Speech

Discussion

Speech Outcome Measures

Reported History of Ear Infections

V

SUMMA

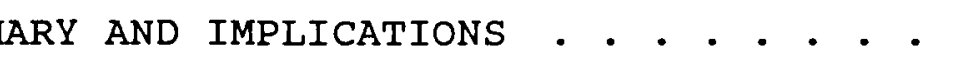

Implications . • . • • . • • • •

Clinical Implications

Research Implications

REFERENCES

APPENDICES

A QUESTIONNAIRE FOR PARENTS OF CHILDREN

15-30 MONTHS OLD . . . . . . . . . . . .

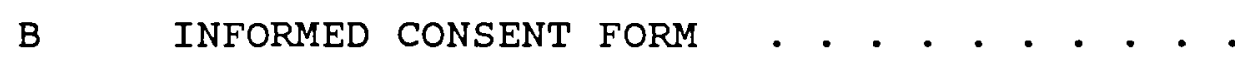

C PARENT QUESTIONNAIRE • . • • • . . . . • •

D 


\section{LIST OF TABLES}

TABLE

PAGE

I Demographic Characteristics . . . . . . 20

II Mean and $\underline{\text { SD }}$ of Reported Ear Infections in Subgroups • • • • • • • • • • • • 27

II Results of a Two-Tailed $t$ Test comparing

the Mean Number of Reported Ear

Infections in the NT

and LT Groups . . . . . . . . . . .

IV Results of a Two-Tailed $t$ Test comparing

the Mean Number of Reported Ear

Infections of OM- Subgroup . . . .

$\mathrm{V}$ Results of a Two-Tailed $t$ Test comparing

the Mean Number of Reported Ear

Infections of OM+ Subgroup . . . .

VI ANOVA Summary Table for Effect of otitis Media . . . . . . . . . . . . .

VII Results of a Two-Tailed $t$ Test for

Independent Subjects comparing the

Mean Goldman Fristoe Percentile

Rank Scores of the OMt and OM-

Subgroups • • • • • • • • • • • • 
Results of a Two-Tailed $t$ Test comparing the Mean Goldman Fristoe Percentile Rank Scores of the NT OM+ Versus OMsubjects • • . • • . • . • . • •

IX Results of a Two-Tailed $t$ Test comparing the Mean Goldman Fristoe Percentile Rank Scores of the LT OM+ Versus OM- Subjects • • • . . . • . • • 


\section{LIST OF FIGURES}

\section{FIGURE}

\section{PAGE}

1. Number of Infections for the $\mathrm{OM}-$ and $\mathrm{OM}+$ Subgroups . . . . . . . . . . . 
CHAPTER I

\section{INTRODUCTION}

Middle-ear disease, particularly otitis media, is a common childhood illness frequently accompanied by a mild, often fluctuating hearing loss. According to McDermott (1983), otitis media is the "inflammation of the middle ear usually accompanied by effusion of serous fluids into the middle ear cavity" (p. 63). The incidence of otitis media is highest during the first 3 years of life, peaking between 6 and 18 months (Klein, 1986). According to Northern and Downs (1984), the occurrence of both ear pathology and hearing loss is age-related, with the highest incidence at about age 2. Roland et al. (1989) characterize otitis media as being silent, or asymptomatic, $25 \%$ of the time and is therefore often undetectable without intense surveillance.

The time period from birth to 2 years is the period when the ability to discriminate between speech sounds on the basis of certain acoustic differences is developing (Menyuk, 1986). At about 1 year children begin to segment the speech stream by using cues, such as tense, plurals, phrase markers, and boundary markers, in order to isolate words to further comprehension. It is during this time that the infant moves from being a preverbal communicator to being a competent user of speech and language (Menyuk, 
1986). This critical period of speech and language development coincides with the period the child is most susceptible to chronic middle-ear infection (zinkus, 1986). If a child experiences intermittent hearing loss and distortion of auditory signals secondary to chronic ear disease during these formative years, he or she may be unable to establish the categories of cues that help in segmenting the stream of speech.

The effects of otitis media on hearing, language, and speech are highly controversial. There is widespread disagreement on issues of treatment, research design, concomitant problems, and predictors of future speech and language problems. Researchers agree, however, that there is a need for more research in order to determine what, if any, consequences result from early otitis media, and how such consequences impact the development of speech and language in children. Toddlers who are "normal" in all other areas but who demonstrate expressive language delays early in life, are one of the groups not adequately researched. A reported history of frequent ear infections before 2 years of age could be a factor in determining which of these children is at risk of continued language problems.

STATEMENT OF PURPOSE

The purpose of this study was to examine the relationship of an early history of otitis media and speech (articulation) development in a group of 3-year-old children 
who were late talkers at 2 years of age. Specifically, scores on the Goldman Fristoe Test of Articulation (GFTA) were compared in late-talking children who have a positive history of middle-ear involvement at 2 years of age with those who do not have a history of middle-ear involvement. The study attempted to answer the following questions:

1. How does the mean number of episodes of "ear infections" reported by parents of children in the latetalker (LT) group compare to the number reported by parents of children in the normal language group?

2. Are there significant differences between scores on the GFTA between groups of late talkers with a positive history of middle-ear involvement and groups of late talkers without a history of middle-ear involvement at 3 years of age suggesting a difference in the acquisition of speech sounds based on history of middle-ear involvement?

3. Are there significant differences between scores on the GFTA between groups of normal talkers with a positive history of middle-ear involvement and groups of normal talkers without a history of middle-ear involvement at 3 years of age suggesting a difference in the acquisition of speech sounds based on a history of middle-ear involvement?

\section{DEFINITION OF TERMS}

For the purpose of this study, the following definitions were used: 
1. Articulation: Using the articulators (teeth, tongue, etc.) to produce speech sounds (Shames \& Wiig, 1986).

2. Ear infections: A lay term for otitis media (Scheidt and Kavanagh, 1986).

3. Late talkers: Those children who, at the time of intake were either: (a) 18-23 months of age and produced fewer than 10 words, or (b) 24 months of age or older and produced fewer than 50 words or no two-word combinations.

4. Normal talkers: Children whose vocabularies exceeded the above criteria.

5. Otitis media: Any infection of the mucousmembrane lining of the middle-ear cleft (Martin, 1985)

6. OM+: Those children who demonstrate at least one of the following: (a) a history of six or more ear infections by parent report; and/or (b) a history of pressure equalization (PE) tubes placed in one or both ears at some time prior to intake; and/or (c) PE tubes were seen during otoscopy.

7. OM-: Children who met none of the criteria for the OM+ group were assigned to the OM- group.

8. Toddler: A child between 12 and 30 months of age. 
CHAPTER II

REVIEW OF THE LITERATURE

Prelinguistic infants appear to have the capacity to discriminate all or most of the acoustic parameters of speech (Strange, 1986). At about 1 year the infant begins to use speech to convey meaning. In order to do this the child must be able to segment the stream of speech and recognize that a sequence of speech sounds is meaningful. Children with fluctuating hearing losses, such as could be caused by chronic otitis media and accompanying fluid in the middle ear, may be unable to establish the categories of cues that help in segmenting the stream of speech and recognizing component sounds, or forming auditory images of the way words are pronounced, at the same rate as normally hearing children since auditory input may be inconsistent due to a poorly functioning middle ear. They may, therefore, be delayed in using these categories in their own speech or in producing accurate approximations of adult target words (Menyuk, 1986).

\section{EPIDEMIOLOGY}

Webster, Bamford, Thyer, and Ayles (1989), suggest that by age 3 more than two-thirds of children have had one episode of middle-ear disease and one-third have had more 
than three episodes. Giebink (1986) states that $70 \%$ of children in the United States experience one or more episodes of otitis media by 5 years of age and that 5-10\% of those children develop chronic otitis media following an otitis media episode.

In their project with the University of Texas at Dallas, Roland et al. (1989) found that $73.5 \%$ of the 483 normal children they studied experienced at least one episode of otitis media by 18 months of age. One-quarter of the episodes were silent and therefore undetectable had it not been for the frequent evaluations ( 11 evaluations in 12 months) .

A 6-year retrospective study of 2,591 children in the Baltimore-Washington area found that the incidence of otitis media was age-dependent. Incidence rates of $84 \%$ for children from birth to 3 years of age, $60 \%$ for children aged 4-7, and a 46\% for children 8-11 years of age were found (Starfield et al., 1984).

Pappas (1985) theorized that if a child has a first episode of otitis media before 18 months of age, he or she tends to be "otitis prone," often having recurring otitis media over an extended period of time. However, children who have no episodes until after 18 months do not have such extended histories. Howie, Ploussard, and sloyer (1975), in their 6-year prospective study, defined the "otitis prone" condition as six or more diagnosed episodes. Ninety percent 
of the "otitis prone" children in the study had their first episode of otitis media before their first birthday.

According to Klein (1986), the frequency of middle-ear infections and the prolonged time spent with middle-ear effusion is of concern, because most children have impaired hearing when fluid is present. The average degree of conductive hearing loss through the speech frequency range (i.e., 500, 1,000, and 2,000 Hertz) was found to be at the 27.6 decibel ( $\mathrm{dB}$ ) hearing level (HL) with a standard deviation of $12.8 \mathrm{~dB} \mathrm{HL}$ in a study of 161 ears (Kokko, 1974).

In summary, otitis media is a common disease which is most prevalent in children from birth to 3 years of age. Children experiencing their first episode of otitis media by 18 months may be more prone to recurrent episodes with the possibility of concurrent fluctuating hearing loss.

Studies Investigating the Effect of Otitis Media on Language Development

Normal language acquisition is dependent upon an intact peripheral and central auditory system. Otitis media and its accompanying effusion cause a mild to moderate conductive hearing loss that degrades the acoustic signal.

Language delay as a consequence of a history of otitis media is thought to especially affect learning vocabulary and morphology (Davis, 1986). As normal hearers and as speakers of the English language, many people may be unaware 
of the degree to which they depend upon repeated exposure when learning new vocabulary or when understanding speech in noise. A child with a conductive loss is at a disadvantage, because he or she has not yet learned all the facets of his or her native language. Learning such things as bound morphemes (e.g., "s," "-ing," "-ed") which are low in intensity (decibels) and high in frequency (Hertz) is difficult without repeated and consistent exposure. For a child with a conductive loss who may have to concentrate just to perceive a degraded signal, the capacity to understand language at any deeper level is interrupted (Bishop \& Edmundson, 1986).

In a study of 27 infants (15 OM+, 12 OM-), Wallace, Gravel, McCarton and Ruben (1988) found a statistically significant relationship between the percentage of time that children experienced bilateral (affecting both ears) episodes of otitis media and scores on an expressive language scale, the Sequenced Inventory of communication Development (SICD). Yet, the OM+ and OM-groups did not differ significantly on either the Bayley Mental

Developmental Index or on the SICD receptive scale, perhaps, the authors suggest, because of the small sample size in their study.

In their study of 69 children with developmental language disorders, Bishop and Edmundson (1986) found that a child's history of otitis media had little detrimental effect on language once the child recovered from his or her 
bout and was hearing normally. However, the authors do suggest that although otitis media alone may not impact language in a significant way, it may be that it is one of many risk factors that may become important when a child is already vulnerable to language delay. These authors also reported that the one background factor they found in common among language-disordered children and not among the normal control group was a family history of language disorder in a close relative (Bishop \& Edmundson, 1986).

Lous, Fiellau-Nikolajsen, and Jeppesen (1988), in a longitudinal study, looked at 28 children who had continuing secretory otitis media or a negative middle-ear pressure of at least 200 decapascals (a unit of measure for pressure) in one or both ears and matched them with a control group that had no ear diseases. Both groups were given a reading test, the Peabody Picture Vocabulary Test-Revised (PPVT-R), and the five verbal subtests of the Wechsler Intelligence scale for Children-Revised (WISC-R). No significant differences were found between the groups on any of the tests.

In a study of 28 expressive language-delayed toddlers, Lynn (1990) found that a reported history of otitis media did not constitute any additional risk of language disorder when the children were evaluated using the Test of Language Development-Primary (TOLD-P) at age 4. Also, no additional risk for immature syntactic expression due to a reported history of otitis media was found when a spontaneous speech 
sample was analyzed for mean length of utterance (Brown, 1973; Miller, 1981).

Studies Investigating the Effect of Otitis Media and Delayed Speech/Articulation

Positive Findings. Researchers have long been concerned about the effects of otitis media on speech and language acquisition because of the high correlation of a mild to moderate hearing loss during the time period that fluid (effusion) may be in the middle ear. Middle-ear effusion would prevent many of the auditory messages from accurately reaching the nervous system (Zinkus, 1986). Deprived of the ability to discern the subtle acoustic differences that provide information for phonetic contrasts, a child's speech acquisition may differ from children who do not experience such losses.

Children who experience episodes of otitis media can be affected by fluctuating hearing losses, bilateral or unilateral (affecting one side) hearing loss, and consequent degradation of the acoustic signals of speech. They may also suffer extended periods of effusion when otherwise asymptomatic and therefore have continued hearing impairment after the otitis media appears outwardly to have disappeared (Zinkus, 1986).

Holm and Kunze (1969) found that children between the ages of 5 and 9 years, with significant histories of otitis media before age 2 , scored more poorly on the Templin-Darley Screening Test, a 50-item test of articulation, than did 
children without a significant history of middle-ear disease. Likewise, Needleman (1977) compared performance scores on the Templin-Darley Screening Test and found that children with histories of otitis media scored significantly poorer than children with no history of otitis media.

Shriberg and Smith (1983) studied the speech samples from a database of 50 children and found that speech-delayed children with a positive history of otitis media made certain sound changes more frequently than speech delayed children without a positive history. They recognize the need for more research yet suggest that possible phonetic power (the intensity of a sound) or perceived pitch (the perception of highness or lowness of a sound) may affect the perception of the OM+ group, resulting in the sound changes. Klein et al. (1988) tested a sample of 196 children at the age of 7 (from a study of 642 children with middle-ear disease) and found that time spent with middle-ear effusion during the first 3 years of life, especially the first year, was associated with significantly poorer scores in many aspects of cognitive ability, speech, and language using the WISC-R, the Goldman-Fristoe-Woodcock, the WUG test, the PPVT-R, the Boston Naming Test, a recorded language sample, and the Metropolitan Achievement Test. However, middle-ear disease occurring between the ages of 4 and 7 showed no significant association with the lower scores.

Silva, Chalmers, and Stewart (1986), in a longitudinal study of children in Dunedin, New Zealand, compared a 
control group with a group having bilateral otitis media with effusion. They examined what differences between the groups in the areas of hearing loss, intelligence, language development, behavior, and speech. The group with bilateral otitis media had consistently poorer speech articulation at ages 5, 7, and 9, with no sign of improvement at age 9. The authors report that children who experience bilateral otitis media tend to have problems in several areas of development (e.g., speech/articulation; reading skills) and remain significantly disadvantaged through the mid-childhood years suggesting that children need to be identified and intervention started at an early age.

In a study of 24 preschool-age children, clarkson, Eimas, and Marean (1989) found that recurrent otitis media interferes with speech perception. These authors divided their subjects into three groups: (a) a control group that had normal language development and no otitis media; (b) a group that had normal language development, but also had recurrent otitis media; and (c) a group that had delayed language development and recurrent otitis media. The third group showed marked differences in the ability to identify and discriminate speech patterns, while the second group fell between the control group and the third group indicating that a history of severe, recurrent otitis media, even without a language delay, produces a reduction in the abilities of young children to perceive speech. The authors concluded that the presence of otitis media makes it 
difficult for children to use phonemic information in perceiving and categorizing speech.

Hasenstab (1987) analyzed samples of spontaneous speech in three groups of children between the ages of 3 and 5 years: (a) children with otitis media, (b) children without otitis media but with language and speech delay, and (c) children with normally developing language and speech. She found that the children with otitis media and the children with delayed language and speech were using significantly more phonological processes than were the normally developing group. Additionally, Hasenstab compared samples of the otitis media group when effusion was present and when middle ears were clear and found that in $30 \%$ of the cases processes increased when effusion was present.

Hubbard, Paradise, McWilliams, Elster, and Taylor (1985) evaluated 24 matched pairs of children with repaired palatal clefts whose treatment was equivalent except that one group received aggressive treatment (i.e., pressure equalization tubes) for otitis media while the second group received traditional (i.e., antibiotic) treatment. The researchers found that the children who received aggressive treatment articulated more consonants correctly than the second group ( $p<0.03)$, presumably because effusion was reduced with the tubes. While the researchers point out that these results cannot be generalized to other groups, they suggest that their findings support the hypothesis that 
early, longstanding otitis media may result in impairments of speech.

Negative Findings. Some theorists (Hoffman-Lawless, Keith \& Cotton, 1981; Needleman, 1977) suggest that because children may only suffer mild to moderate hearing losses during episodes of otitis media with hearing thresholds returning to normal after an episode, there should be little, if any, long-term effect from signal deprivation.

Ventry (1980) found methodological shortcomings with nearly every study linking otitis media with speech and language delays that was done prior to 1980 . He disputes the findings of this previous research and suggests that future researchers: (a) choose subjects carefully, making sure they are as closely matched as possible on all things except the classification that differentiates the group;

(b) consider differences in hearing sensitivity when presenting levels of all test stimuli; (c) use carefully calibrated equipment; and (d) generalize data cautiously.

McWilliams (1983), in a review of research on the effect of otitis media on articulation, states that clinical evidence suggests that articulation development is influenced by conductive hearing loss, but that the relationship is undoubtedly modified by many variables (e.g., severity of loss; length of time the otitis media persists; the timing, success, and frequency of treatment; the overall developmental integrity of the child, etc.) that have yet to be identified. According to McWilliams, we can 
suspect, but cannot confirm, a link between otitis media and articulation until appropriate research is carried out.

Roberts, Burchinal, Koch, Footo, and Henderson (1988) reported on a longitudinal study of 55 children attending a daycare program who were monitored 5 days a week for episodes of otitis media. The children were given a yearly speech assessment with the GFTA. No significant correlations between total episodes of otitis media and consonants in error or total phonological processes were found, although some evidence suggested that early otitis media might be associated with the total number of phonological processes used by children between the ages of 4.5 and 8 years of age.

A Danish study of children with and without otitis media showed a minor variation in pronunciation between the OM+ and OM- groups. Researchers saw background factors, not the presence of otitis media, as having more significance in affecting pronunciation (Brahe Pedersen \& Olsen, 1990).

Webster et al. (1989) evaluated the developmental sequelae of otitis media by matching $O M+$ and $O M-$ groups who were then tested with a battery of tests including a Domain Phonic Test and a phonological encoding during reading task using procedures developed by Doctor and coltheart (1980). No significant differences were found between oM+ children and controls on either the test or the Doctor and coltheart task. 
In a study of 694 -year-old children with specific developmental language disorders and otitis media, Bishop and Edmundson (1986) computed percentage consonants correct and analyzed occurrence of phonological processes with the Newcastle Speech Assessment test. When compared with a control group, no difference was found in occurrence of phonological processes or in the frequency of occurrence of the sound changes (as described in the study by shriberg and Smith, 1983).

\section{SUMMARY}

A review of the literature revealed a lack of definitive evidence linking otitis media with delayed speech. Controversy exists about whether variables such as age, sex, race, season, genetic and familial factors, feeding techniques, or day care, may interact with otitis media. Further controversy exists over methodological issues: (a) the length of time a child spends with fluid in his or her middle ear, (b) the amount of hearing loss caused by the middle-ear fluid, and (c) whether the otitis is unilateral or bilateral. Researchers do agree, however, on the need for more studies. Since otitis media alone may not impact speech, determining whether a history of otitis media increases the risk of delayed speech in a group of children, such as late talkers, who are already at risk may lead to better understanding of this complex situation. 
CHAPTER III

METHODS AND PROCEDURES

SUBJECTS

The 52 3-year-old children in this study are all participants in an on-going, longitudinal study being conducted at Portland State University. These children were first seen at 2 years of age when they were designated as either "late" or "normal" speakers, based upon their expressive vocabularies as reported on the Questionnaire for Parents of Children 15-30 Months old (see Appendix A).

Children who were between the ages of 18 and 23 months at the time of intake were included in the LT group if their parents reported that they produced fewer than 10 different words. Children who were 24-34 months of age were included in the LT group if their parents reported that they had expressive vocabularies of less than 50 words, or that they used no two-word combinations. Children whose vocabularies exceeded the above criteria were included in the NT group.

\section{Subject Recruiting}

Three methods were used to recruit subjects for the ongoing study. The first method was to distribute questionnaires to three pediatric clinics within the Portland metropolitan area. Questionnaires were distributed 
by nurses or receptionists to parents who brought in their children for well-child visits. In addition to information about their children's expressive vocabularies, the questionnaire asked parents if they would be interested in participating in later parts of the study.

The second method used to recruit subjects was to broadcast announcements over a local radio station explaining the study and requesting subjects. The final method was to publish an article in the oregonian newspaper describing the study and requesting subjects. Parents who responded to either the radio or newspaper announcement were contacted by telephone at which time they were asked the questions on the questionnaire. Responses were recorded on the response form by the interviewer.

All children who met the criteria for the LT group were invited to participate in the study. A group of subjects was then selected from the pool of interested normal talkers to match the LT group in terms of sex, age, race, socioeconomic status and birth order. Parents then brought their children to Portland State University for an intensive intake assessment.

\section{Description of Subjects}

Twenty-seven of the children who were placed in the LT group at age 2 participated in the follow-up study when they were 3 years of age. Twenty-five of the children in the NT group participated in the follow-up study. Demographic 
characteristics are displayed in Table I. The average age of the subjects at intake in this study was 26 months. They were middle class in terms of socioeconomic status. The subjects included 14 females and 38 males. Ninety-six percent of subjects were Caucasian. The mean expressive vocabulary size as measured by the Language Development Survey (IDS) (Rescorla, 1989) was 205 words for the NT group and 23.9 for the LT group.

PROCEDURES

\section{Intake Procedures}

During the first of three intake sessions, the study was explained orally and in writing to the parent of each subject, and the parent signed a form giving permission for that child to participate in the study (see Appendix B). The parent then completed a questionnaire concerning socioeconomic status and the child's medical history, including information about the child's history of ear infections (see Appendix $c$ ). Language assessments were also conducted during this visit.

Parents also completed the Language Development Survey (Rescorla, 1989) (see Appendix D). The Language Development Survey (LDS) is a checklist of 300 of the most common words in children's early vocabularies and has been reported to show excellent reliability, validity, sensitivity, and 
TABLE I

DEMOGRAPHIC CHARACTERISTICS

NT

LT

Age at intake

Range

$19-34$

$19-33$

$\underline{\mathrm{M}}$

25.5

26.2

$\underline{\text { SD }}$

$4 \cdot 1$

3.8

SES ${ }^{\mathrm{a}}$

$\underline{\mathbf{M}}$

2.4

2.9

$\underline{\text { SD }}$

1.3

1.0

Sex

Male

$64 \%$

858

Female

$36 \%$

$15 \frac{8}{6}$

Race

white

$96 \%$

$96 \%$

Expressive vocabulary

$\underline{\mathrm{M}}$

205

23.9

$\underline{S D}$

78.7

28.9

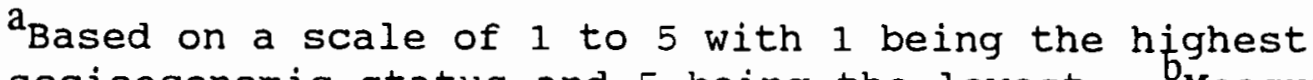
socioeconomic status and 5 being the lowest. $b_{\text {Measured by }}$ the Language Development Survey (Rescorla, 1989). (See Appendix D.) 
specificity in distinguishing normal and language-delayed 2-year-olds (Rescorla, 1989). Parents are instructed to circle the words on the list that their children could say, and to indicate whether or not the children combined two words. The same criteria for group assignment which were applied to vocabularies reported on the initial parent questionnaire were applied to vocabularies reported on the LDS. Children were included in the LT group only if they continued to meet these criteria. Children who were 18-23 months of age were included in the LT group if they produced fewer than 10 different words and children who were 24-34 months of age were included in the LT group if they produced less than 50 words, or used no two-word combinations. The second session included a hearing screening. Audiometric screening was performed in a sound proof booth in sound field using speech stimuli and visual reinforcement audiometry. Subjects were screened at $15 \mathrm{Db} \mathrm{HL}$. Speech awareness thresholds were obtained for subjects who failed the screening test at $15 \mathrm{Db} \mathrm{HL}$. Screening was either performed by a certified audiologist or by a graduate student of audiology under the supervision of a certified audiologist. Tympanograms were obtained on both ears. Tympanograms were not obtainable on 10 subjects because of excessive vocalization.

During the final assessment session the Bayley scales of Infant Development (Bayley, 1969) was administered by a psychologist. Each of the subjects demonstrated normal 
intellectual functioning by obtaining a score of 85 or better. Subjects were screened informally for signs of neurological impairment, autism, and any disability which might preclude normal language development.

\section{outcome Procedures}

As part of the longitudinal study, the speech and language of each child was evaluated at age 3 . The average age of subjects during these follow-up evaluations was 38 months $(\underline{S D}=2.4)$. There was no significant difference between the mean age of subjects in the NT group and those in the LT group.

The GFTA (Goldman \& Fristoe, 1969) was performed by a graduate research assistant in accordance with procedures specified in the test manual. Rapport was established with the subjects before testing began. Tests were administered in a quiet room at Portland State University with the subject and examiner facing one another across the corner of a table.

\section{Procedures for Present study}

The present study analyzed data collected during the intake and outcome assessments mentioned above. Children within each diagnostic group were further divided into an otitis media positive (OM+) and an otitis media negative (OM-) group based upon information provided on the parent questionnaire (see Appendix $c$ ) in conjunction with 
audiologic information obtained during the intake evaluation.

Since the medical history questionnaire was designed for the larger longitudinal study and not specifically for the present investigation, it was general in nature and included only two questions specifically related to ear infections. These were:

1. How many ear infections has your child had?

2. Is the child currently being treated for ear infections?

The questionnaire also asked the parent to list any medical problems. Those responses to the first question which were other than a single number were interpreted as follows:

1. If a range of values was given, the mean value rounded to the nearest whole number was used.

2. If two consecutive numbers were reported (i.e. $2-3)$, the higher value was assigned.

3. "Many" and "chronic" were assigned a value of 10 episodes. Precedent for assigning this arbitrary value was set by Bishop and Edmundson (1986).

Children were included in the oM+ group if they met one of the following criteria:

1. Parent reported that the child had a history of 6 or more ear infections in the first 2 years of life.

2. Parent reported that the child had pressure equalization (PE) tubes placed in one or both ears at some time prior to intake; or PE tubes were seen during otoscopy. 
Distribution of the number of ear infections in the om+ and OM-groups is depicted in Figure 1. Children who met none of the criteria for the OM+ group were assigned to the OMgroup.

These criteria are adapted from indicators used in a study by Shriberg and Smith (1983). The criteria used for this study were designed to differentiate those subjects who were likely to have experienced frequent and persistent episodes of otitis media from those who had a history of infrequent episodes. Six ear infections was selected as a cutoff because it marked a natural break in the distribution of values reported by parents in the present study and is comparable to the number used in other studies (Brandes \& Ehinger, 1981; Shriberg \& Smith, 1983; Zinkus \& Gottlieb, $1980)$.

A report of pressure equalization tube placement irrespective of the number of reported ear infections was considered an adequate indication of a positive history of otitis media since surgery presumably would not have been performed without such a history. Information concerning pressure equalization tubes was obtained from the parent questionnaire or from information provided by the audiologist based upon otoscopic inspection.

\section{Equipment}

A Maico clinical audiometer (Model 24-B), calibrated to meet American National standards Institute, Inc. (1972) 


$$
\begin{array}{ll}
0 & 0 \\
0 & 0 \\
0 & 0 \\
+ & 1 \\
+ & 0
\end{array}
$$

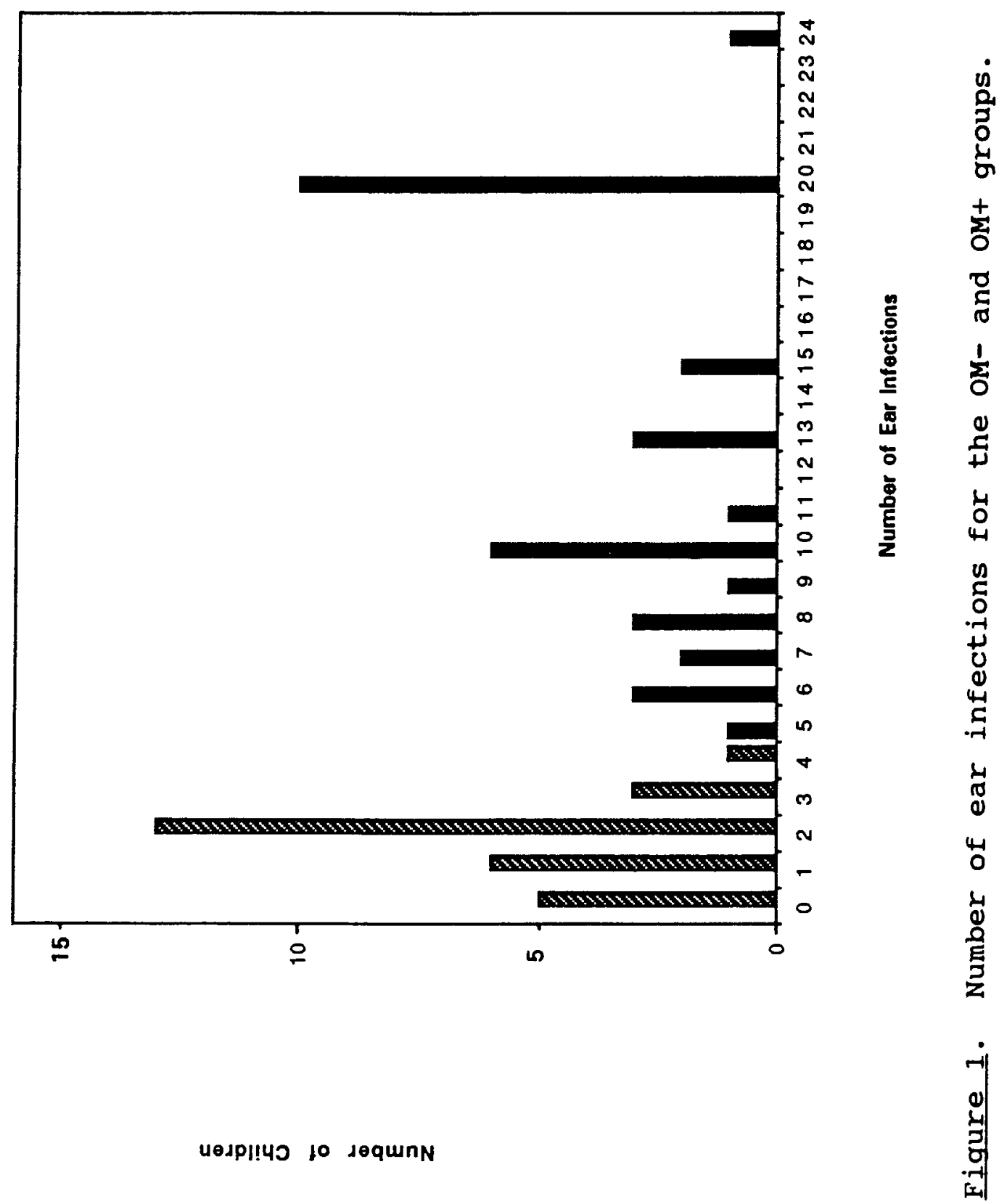


specifications, was used to determine hearing levels at speech frequencies in sound field through loudspeakers using visual reinforced audiometry. A Saico Impedance Bridge (Model SI-22), calibrated to manufacturer's specifications, was used to obtain tympanograms. 


\section{CHAPTER IV}

\section{RESULTS AND DISCUSSION}

\section{RESULTS}

\section{Reported History of Ear Infections}

Eleven of the parents responded to, "How many ear infections has your child had?" with something other than a single number. These responses were interpreted according to the procedures detailed in chapter III. The mean number of ear infections reported for children in the NT and IT groups are shown in Table II. A two-tailed $\underline{t}$ test comparing

TABLE II

MEAN AND SD OF REPORTED EAR

INFECTIONS IN SUBGROUPS

\begin{tabular}{|c|c|c|c|}
\hline Group & $\underline{n}$ & $\underline{\mathbf{M}}$ & $\underline{S D}$ \\
\hline NT & & 4.6 & 4.6 \\
\hline $\mathrm{OM}+$ & 10 & 9.4 & 3.4 \\
\hline OM- & 15 & 1.3 & 0.9 \\
\hline $\mathrm{LT}$ & & 6.9 & 6.1 \\
\hline $\mathrm{OM}+$ & 14 & 11.4 & 5.1 \\
\hline$O M-$ & 13 & 1.9 & 1.1 \\
\hline
\end{tabular}


the mean number of ear infections reported for children in the NT and LT groups was computed using an alpha level of .05. The results of the comparison are shown in Table III. The test statistic indicated that no significant difference exists in the number of ear infections reported for the two major diagnostic groups, normal versus late talker. Similarly, there were no differences between the number of episodes of otitis media reported for the OM+ subgroup when comparing normal talkers with late talkers, or for the oMsubgroup when these two diagnostic categories were compared. The results of the comparisons are shown in Table IV and Table V.

The Effect of Otitis Media on Speech

In order to determine whether there were significant differences between percentile rank scores on the GFTA based

\section{TABLE III}

RESULTS OF A TWO-TAILED $t$ TEST COMPARING THE MEAN NUMBER OF REPORTED EAR INFECTIONS IN THE NT AND LT GROUPS

\begin{tabular}{lccc}
\hline Group & $\underline{\mathrm{M}}$ & $\begin{array}{c}\text { t-test } \\
\text { statistic }\end{array}$ & Significance? \\
\hline $\mathrm{NT}$ & 4.56 & 1.54 & \\
$\mathrm{LT}$ & 6.85 & & No \\
\hline
\end{tabular}


TABLE IV

RESULTS OF A TWO-TAILED $t$ TEST COMPARING THE

MEAN NUMBER OF REPORTED EAR INFECTIONS

OF OM- SUBGROUP

\begin{tabular}{lccc}
\hline Group & $\underline{\text { M }}$ & $\begin{array}{c}\text {-test } \\
\text { statistic }\end{array}$ & Significance? \\
\hline NT OM- & 1.3 & 1.54 & \\
LT OM- & 1.9 & & No \\
\hline
\end{tabular}

$* \underline{p}<0.268$.

TABLE V

RESULTS OF A TWO-TAILED $t$ TEST COMPARING THE

MEAN NUMBER OF REPORTED EAR INFECTIONS

OF OM+ SUBGROUP

\begin{tabular}{lccc}
\hline Group & $\underline{\text { M-test }}$ & $\begin{array}{c}\text { t-tatic } \\
\text { statistic }\end{array}$ & Significance? \\
\hline NT OM+ & 9.4 & 1.09 & No \\
LT OM+ & 11.4 & & \\
\hline
\end{tabular}

$\star \underline{p}<0.56$ 
on a history of otitis media an Analysis of variance (ANOVA) was performed. The results of the ANOVA are shown in Table VI. The data indicate that the LT group scored significantly more poorly overall than the NT group. However, there was no significant difference in GFTA percentile rank scores based on a history of otitis media, nor was there an interaction of otitis media history with diagnostic group.

To follow up these findings, $t$ tests for differences between means were done. Table VII shows this comparison for the NT versus LT scores, overall. This result reflects the ANOVA find that normal talkers score higher on the GFTA percentile scores than late talkers at age 3 . Table VIII

TABLE VI

ANOVA SUMMARY TABLE FOR EFFECT OF OTITIS MEDIA Mean

Source $\underline{F}$ square significance

$\begin{array}{lccc}\text { Group } & 1 & 18875.604 & <.0001 \\ \text { History of otitis media } & 1 & 451.552 & <.4185 \\ \text { Group by history } & 1 & .215 & <.9859 \\ \text { Error } & 48 & 677.937 & \end{array}$

Note. Dependent variable: Goldman Fristoe Test of Articulation percentile rank scores. 
TABLE VII

RESULTS OF A TWO-TAILED $t$ TEST FOR INDEPENDENT SUBJECTS COMPARING THE MEAN GOLDMAN FRISTOE PERCENTILE

RANK SCORES OF THE OM+ AND OM- SUBGROUPS

\begin{tabular}{lcccc}
\hline Group & $\underline{M}$ & $\underline{S D}$ & $\begin{array}{c}\text { t-test } \\
\text { statistic }\end{array}$ & Significance? \\
\hline NT & 55.4 & 33.1 & -5.37 & Yes \\
LT & 16.1 & 16.0 & & \\
\hline
\end{tabular}

* $\underline{\mathrm{p}}<.0001$.

TABLE VIII

RESULTS OF A TWO-TAILED $t$ TEST COMPARING

THE MEAN GOLDMAN FRISTOE PERCENTILE

RANK SCORES OF THE NT OM+

VERSUS OM- SUBJECTS

\begin{tabular}{lllll}
\hline Group & M & $\underline{\text { SD }}$ & $\begin{array}{c}\text { t-test } \\
\text { statistic }\end{array}$ & Significance? \\
\hline NT OM+ & 51.9 & 32.7 & -0.43 & No \\
NT OM- & 57.7 & 34.2 & & \\
\hline
\end{tabular}

$* \underline{p}<0.134$. 
shows the comparison for NT OM+ versus OM- subjects on the GFTA percentile scores. Table IX gives this comparison for the LT OM+ versus OM- subgroups. These comparisons show that, as the ANOVA found, there is no significant difference in articulation performance based on otitis media history within each diagnostic group.

\section{DISCUSSION}

\section{Speech outcome Measures}

The main research questions asked in this study looked at whether there are significant differences between scores on the GFTA between groups of late talkers with and without a positive history of otitis media, and groups of normal talkers with and without a positive history of otitis media at 3 years of age indicating a difference in the acquisition

\section{TABLE IX}

RESULTS OF A TWO-TAILED $t$ TEST COMPARING THE MEAN GOLDMAN FRISTOE PERCENTILE RANK SCORES OF THE LT OM+ VERSUS OM- SUBJECTS

\begin{tabular}{|c|c|c|c|c|}
\hline Group & $\underline{\mathbf{M}}$ & $\underline{\mathrm{SD}}$ & $\begin{array}{c}\text { t-test } \\
\text { statistic }\end{array}$ & Significance? \\
\hline $\mathrm{LT} \mathrm{OM}+$ & 13.2 & 11.1 & -0.96 & No \\
\hline LT OM- & 19.3 & 20.2 & & \\
\hline
\end{tabular}

$\star \underline{p}<0.70$. 
of speech sounds based on history of middle-ear involvement. A two-tailed $\underline{t}$ test comparing the mean GFTA percentile rank score of normal and LT groups was performed. A significant difference $(\mathrm{p}<.05)$ was found between the two groups indicating that late talkers are much poorer in articulation than normal talkers. An analysis of variance was performed to determine if an interaction between the subgroups and their history of otitis media could be found. No significance was found suggesting that ear infections alone do not seem to account for the poorer articulation in late talkers.

\section{Reported History of Ear Infections}

Another research question addressed how the mean number of episodes of "ear infections" reported by parents of children in the LT group compare to the number reported by parents of children in the NT group. The mean number of ear infections reported by the parents of the LT and NT subjects was compared. While the LT subjects were reported to have slightly more ear infections than the NT subjects, this difference did not reach a significant level. These results compare with the results of Bishop and Edmundson (1986) who found no significant difference in the number of reported ear infections in language-disordered and control children. It is possible that the comparison did not reach a significant level because of variables that may interact with otitis media such as season of the year, genetic or 
familial factors, or day care attendance, that were not controlled for in this study. 


\section{CHAPTER V \\ SUMMARY AND IMPLICATIONS}

SUMMARY

Researchers agree that otitis media is an extremely prevalent disorder among young children, yet there is no agreement on the effect otitis media has on speech development. The lack of definitive evidence indicates the need for continued research.

This study examined the relationship between an early history of otitis media and the speech development of a group of late talkers. The 27 LT toddlers in this group, while otherwise normal, were late to begin to speak. Each of the subjects was placed into one of two subgroups, depending upon their reported experience with otitis media. When the children were 3 years old, they were evaluated using the GFTA. A similar group of 25 children who had a history of normal language development was also examined.

This study found that a reported history of otitis media did not constitute any additional risk of speech disorder to the group of LT children. There were no differences in speech outcome score for OM subgroups within the LT group, or between OM+ and OM- subgroups in the 
normally speaking group. However, late talkers are at risk for articulation delay, regardless of otitis media history.

\section{IMPLICATIONS}

\section{Clinical Implications}

The results of this study indicate that children who demonstrate expressive language delays at age 2 are at risk for immature articulatory development at age 3. We find no evidence that a history of otitis media adds to this risk or constitutes any additional risk of speech disorder. These results suggest the need to continue to monitor the language and speech (articulation) development of late talkers regardless of their experience with otitis media. For children who are developing normally at age 2 , an early history of otitis media does not appear to delay articulation. In a study examining the language outcomes of these same children, Lynn (1990) found that otitis media may interact with factors such as low socioeconomic status to constrain their receptive language growth.

The results of this study and the Lynn (1990) study suggest that while research into the effects of otitis media is inconclusive, parents could be counseled that it does not appear that otitis media alone is cause for language and articulation delays. Any child, regardless of otitis media history, with slow language development should be monitored carefully throughout the third year and receive intervention soon after the third birthday if substantial improvement is 
not seen. However, since otitis media is a complex problem and may interact with many variables, parents also could be counseled that continued audiometric, articulation, and language monitoring is important for the child who is a late talker. Likewise, language stimulation/enrichment programs may be helpful especially during those times that a child's hearing may be depressed due to otitis media.

\section{Research Implications}

otitis media may be one of a number of variables that interact to delay articulation and language. Since past researchers have had difficulties with research designs and interpretations due to complex interactions of variables, more research needs to be attempted that will try to control for the many variables. Some of the shortcomings of this study include its retrospective nature, briefness of medical history, and the assignment to subgroups based on parent report.

Because the risk of speech and language delay may be dependent on how much of a hearing loss an individual sustains during and after episodes of otitis media, research should investigate actual hearing thresholds of subjects on an ongoing basis. This could be done with a well designed prospective study involving children identified at age 2 as late talkers. 
The present study raises several other questions which could be explored in future studies. Among these questions are:

1. How accurate are parent reports of ear infections? studies could compare retrospective parent reports with medical chart reviews and intensive otologic evaluations.

2. Are there specific speech sounds (or categories of speech sounds) with which late talkers have difficulty? Do these sounds differ for OM+ versus OM- groups?

3. For children like those in this study, how do reports of additional ear infections during the third year of life compare to those reported for the first 2 years?

4. Does the inclusion of this additional data lead to significant differences in speech outcomes?

The present study did not take into account whether the otitis media was unilateral or bilateral, or the hearing levels of the subjects immediately preceding testing with the GFTA. Comparing children with unilateral versus bilateral conditions would be a significant contribution. otitis media continues to be an ongoing problem, especially for young children. Researchers disagree about the long-term effects of otitis media and its contribution to speech (articulation) and language problems. While the results of this study indicate that a history of otitis media does not constitute any additional risk of speech (articulation) disorder in expressive language-delayed children, it may be one of many variables, such as family 
history, that interact with speech and language that may increase the already substantial risk for speech (articulation) delay in such children. 
REFERENCES

American National Standards Institute, Inc. (1972). Specifications for audiometers (ANSI S3.6-1969). New York: ANSI.

Bishop, D., \& Edmundson, A. (1986). Is otitis media a major cause of specific developmental language disorders? British Journal of Disorders of Communication, 21, 321-338.

Brahe Pedersen, C., \& Olsen, V. (1990). Danish approach to treatment of secretory otitis media. Annals of otology, Rhinology \& Laryngology, 99 (Suppl. 146, Part 2), 16-17.

Brandes, P., \& Ehinger, D. (1981). The effects of early middle ear pathology on auditory perception and academic achievement. Journal of Speech and Hearing Disorders, $46,250-257$.

Brown, R. (1973). A first language: The early stages. Cambridge: Harvard University Press.

Clarkson, R. Eimas, P., \& Marean, G. (1989). Speech perception in children with histories of recurrent otitis media. Journal of the Acoustical society of America, $\underline{\text { 85 }}(2), 926-933$.

Davis, J. (1986). Remediation of hearing, speech, and language deficits resulting from otitis media. In $\mathrm{J}$. Kavanagh (Ed.), otitis media and child development (pp. 182-191). Parkton, MD: York Press.

Doctor, E. A., \& Coltheart, M. (1980). Children's use of phonological encoding when reading for meaning. Memory and Cognition, 8 (3), 195-209.

Giebink, G. (1986). Prevention and medical treatment of otitis media. In J. Kavanagh (Ed.), otitis media and child development (pp. 176-181). Parkton, MD: York Press.

Goldman, R., \& Fristoe, M. (1986). Goldman Fristoe Test of Articulation. Circle Pines, MN: American Guidance Service. 
Hasenstab, M. (1987) . Language learning and otitis media. Boston: College-Hill.

Hoffman-Lawless, K. , Keith, R. , \& Cotton, R. (1981). Auditory processing abilities in children with previous middle-ear effusion. Annals of otology, Rhinology and Laryngology, 90, 543-545.

Holm, V., \& Kunze, L. (1969). Effects of chronic otitis media on language and speech development. Pediatrics, $\underline{43}, 833-839$.

Howie, V., Ploussard, J., \& sloyer, J. (1975). The "otitis-prone" condition. American Journal of Diseases of Children, 129, 676-678.

Hubbard, T., Paradise, J., MCWilliams, B., Elster, B., \& Taylor, F. (1985). Consequences of unremitting middle-ear diseases in early life. New England Journal of Medicine, 312, 1529-1534.

Klein, J. (1986). Risk factors for otitis media in children. In J. Kavanagh (Ed.), otitis media and language development (pp. 45-50). Parkton, MD: York Press.

Klein, J., Chase, C., Teele, D., Menyuk, P., Rosner, B. , \& The Greater Boston otitis Media study Group. (1988). otitis media and the development of speech, language, and cognitive abilities at seven years of age (pp. 396-397). In D. Lim (Ed.), Recent advances in otitis media. Toronto: B. C. Decker Inc.

Kokko, E. (1974). Chronic secretory otitis media in children. Acta Otoloaryngologica, 372(Suppl. 327), 7-44.

Lous, J., Fiellau-Nikolajsen, M. \& Jeppesen, A. (1988) . Secretory otitis media and verbal intelligence: A six year prospective case control study. In D. Lim (Ed.), Recent advances in otitis media ( $\mathrm{pp}$. 393-395). Toronto: B. C. Decker Inc.

Lynn, T. (1990). Otitis media and language development in late talkers. Unpublished master's thesis. Portland state University, OR.

MCDermott, J. (1983). Physical and behavioral aspects of middle ear disease in school children. Journal of School Health, $\underline{53}(8), 463-466$. 
McWilliams, B. (1983). Effect of otitis media on articulation development in children. In C. D. Bluestone, J. O. Klein, J. L. Paradise, H. Eichenwald, F. H. Bess, M. P. Downs, M. Green, J. Berko-Gleason, I. M. Ventry, S. W. Gray, B. J. McWilliams, \& G. A. Gates (Contributors to Special Article), Workshop on Effects of Otitis Media on the Child, Pediatrics, 71, 646-647.

Menyuk, P. (1986). Predicting speech and language problems with persistent otitis media. In J. Kavanagh (Ed.), otitis media and child development (pp. 83-96). Parkton, MD: York Press.

Miller, J. (1981). Assessing language production in children. Austin, TX: Pro-Ed.

Needleman, H. (1977). Effects of hearing loss from early recurrent otitis media on speech and language development. In B. Jaffe (Ed.), Hearing loss in children. Baltimore, MD: University Park Press.

Northern, J., \& Downs, M. (1984). Hearing in children. Baltimore, MD: Williams \& Wilkins.

Pappas, D. (1985). Diagnosis and treatment of hearing impairment in children. San Diego, CA: College-Hill Press.

Rescorla, L. (1989). The language development survey: A screening tool for delayed language in toddlers. Journal of Speech and Hearing Disorders, 54, 587-597.

Roberts, J., Burchinal, M., Koch, M., Footo, M., \& Henderson, F. (1988). Otitis media in early childhood and its relationship to later phonological development. Journal of Speech and Hearing Disorders, 53, 424-432.

Roland, P., Finitzo, T., Friel-Patti, S., Brown, K., Stephens, K., Brown, O., \& Coleman, M. (1989). otitis media. Archives of Otolaryngology Head and Neck Surgery, 115(9), 1049-1054.

Scheidt, P. \& Kavanagh, J. (1986). Common terminology for conditions of the middle ear. In J. Kavanagh (Ed.), otitis media and child development, (pp. xv-xvii). Parkton, MD: York Press.

Shriberg, L., \& Smith, A. (1983). Phonological correlates of middle-ear involvement in speech-delayed children: A methodological note. Journal of Speech and Hearing Research, 26, 293-297. 
Silva, P., Chalmers, D., \& Stewart, I. (1986). Some audiological, psychological, educational and behavioral characteristics of children with bilateral otitis media with effusion: A longitudinal study. Journal of Learning Disabilities, 19(3), 165-169.

Starfield, B., Katz, H., Gabriel, A., Livingston, G., Benson, P., Hankin, J., Horn, S., \& Steinwachs, D. (1984). Morbidity in childhood: A longitudinal view. New England Journal of Medicine, 310, 824-829.

Strange, W. (1986). Speech input and the development of speech perception. In J. Kavanagh (Ed.), otitis media and child development (pp. 12-26). Parkton, MD: York Press.

Ventry, I. (1980). Effects of conductive hearing loss: Fact or fiction. Journal of Speech and Hearing Disorders, 45, 143-156.

Wallace, I., Gravel, J., McCarton, C., \& Ruben, R. (1988). otitis media and language development at 1 year of age. Journal of Speech and Hearing Disorders, 53, 245-251.

Webster, A., Bamford, J., Thyer, N., \& Ayles, R. (1989). The psychological, educational, and auditory sequelae of early persistent secretory otitis media. Journal of Child Psychology and Psychiatry, 30, 529-546.

Zinkus, P. (1986). Perceptual and academic deficits related to early chronic otitis media. In J. Kavanagh (Ed.), Otitis media and child development (pp. 107116). Parkton, MD: York Press.

Zinkus, P. \& \& Gottlieb, M. (1980). Patterns of perceptual and academic deficits related to early chronic otitis media. Pediatrics, 66, 246-253. 
APPENDIX A

QUESTIONNAIRE FOR PARENTS OF

CHILDREN 15-30 MONTHS OLD 
Questionnaire for Parents of

Children 15-30 Months old

What is your child's:

first name?

date of birth?

Mother's (or primary parent's) full name?

Mother's (or primary parent's phone number?

Mother's occupation?

Father's occupation?

How many different words can your child say? (It's okay if the words aren't entirely clear, as long as you can understand them.)

none

less than 5

$10-30$

5-10

$30-50$

If your child says fewer than 10 words, please list them here:

Does your child put words together to form short "sentences"?

Yes No

If yes, please give three examples here:

Would you be interested in participating in later parts of this study? 
APPENDIX B

INFORMED CONSENT FORM 
INFORMED CONSENT

I, hereby agree to

serve as a subject in the research project on language development in young children conducted by Rhea Paul.

I understand that the study involves seeing my child yearly for speech and language evaluation and videotaping conversations between me and my child. I understand that these tapes will be transcribed for analysis of my child's spoken language patterns.

It has been explained to me that the purpose of the study is to learn whether children who begin talking late are at risk for later learning problems.

I may not receive any direct benefit from participation in this study, but my participation may help to increase knowledge which may benefit others in the future.

Dr. Paul has offered to answer any questions I may have about the study and what is expected of me in the study. I have been assured that all information I give will be kept confidential and that the identity of all subjects will remain anonymous.

I understand that I am free to withdraw from participation in this study at any time without jeopardizing my relationship with Portland State University.

I have read and understand the foregoing information.

Date:

Signature:

If you experience problems that are the result of your participation in this study, please contact the secretary of the Human Subjects Research and Review Committee, office of Grants and Contracts, 303 Cramer Hall, Portland State University, 464-3417. 
APPENDIX C

PARENT QUESTIONNAIRE 


\section{PARENT QUESTIONNAIRE}

Dear Parents,

Please answer the questions on this form to the best of your ability. All answers will be held strictly in confidence and used for statistical purposes only. You need not put your full name anywhere on the form; only the child's first name, last initial and birth date are needed for identification purposes.

Today'g date

Child'g first name

Mother's address:

Mother's telephone

Mother's date of birth

Mother's marital status

Mother's level of education:

Mother's employment:

not employed

employed part-time

employed full-time

occupation (past or present):

gross income per year:
Child's birth date

Child's sex

Father's address:

Father's telephone

Father's marital status

Father's level of education:

Father's employment:

not employed

employed part-time

employed full-time

occupation (past or present):

gross income per year:

Please give sex and ages of the child's older brothers and sisters:

Please give sex and ages of the child's younger brothers and sisters:

How many hours per week is the child regularly cared for in daycare or by a babysitter?

What is the main language spoken at home?

If any other languages are spoken at home, please list them:

Were there any problems during your pregnancy with this child? If so, please list them:

Were there any problems (including prematurity) during the child's birth? If so, please list them (e.g., how many weeks premature was the birth?)

Were there any medical problems after birth? If so, please list them:

How many ear infections has the child had?

Is the child currently being treated for ear infections?

Has the child lived away from parents for more than a few weeks? If so, please explain:

Are you worried at all about the child's speech?

Has anyone in your family been slow to learn to talk? If so, who? 


\section{APPENDIX D}

LANGUAGE DEVELOPMENT SURVEY

Source: Rescorla, L. (1989). Language development survey. Journal of Speech and Hearing

Disorders, 54, 587-599, pp. 598-599. 


\section{Language Development Survey}

Dear Parent,

We are engaged in research on expressive language development in 2-year-old children. We are especially interested in learning more about children who are slow in talking. We invite you to help us by completing this form and the vocabulary checklist on the back. Participation is entirely voluntary, and all information given will be strictly confidential.

Date Child's name
Mother's name
Address
Telephone
Date of birth
Marital status
Level of education completed
Employment:
$\quad$ Not employed
Employed part-time
Employed full-time
Occupation

Sex __ Age

Father's name

Address

\section{Telephone}

Date of birth

Marital status

Level of education completed

Employment:

Not employed

Employed part-time

Employed full-time

Occupation

Please give age and sex of other children in family

Has anyone in your family been slow in learning to talk?

If so, who?

Was your child premature?

How many weeks early?

How many ear infections has your child had?

Is child in daycare or cared for regulariy by babysitter?

If so, how many hours per week?

What language is spoken in your home?

Please list languages spoken if other than English

Are you worried about your child's language development?

PLEASE COMPLETE VOCABULARY CHECKLIST ON THE REVERSE SIDE.

Please check off each word your child says. Don't include words your child can understand but not say. It's all right to count words that aren't pronounced clearly. Don't count words which your child repeats after you in imitation but does not say spontaneously. 
Vocabulary Checklist

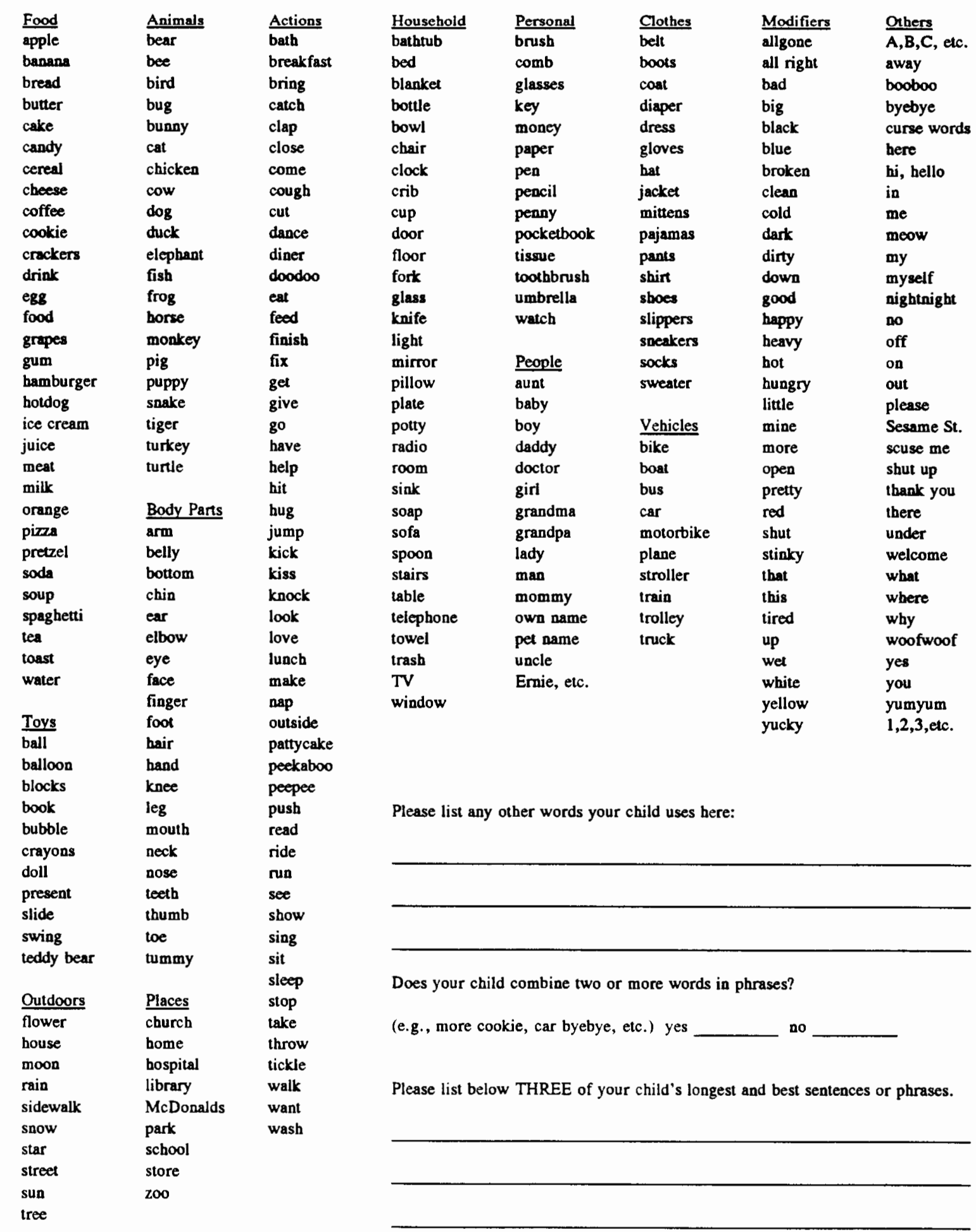

